\title{
Volatile constituents and anti candida activity of the aerial parts essential oil of Dittrichia graveolens (L.) Greuter grown in Iran
}

\author{
Nasrin Aghel $^{1 *}$, Ali Zarei Mahmoudabadi ${ }^{2}$ and Loobat Darvishi ${ }^{1}$ \\ ${ }^{1}$ Medicinal Plant Research Center, Department of Pharmacognosy, School of Pharmacy, Jundishapour Medical \\ Sciences University, Ahwaz, Iran. \\ ${ }^{2}$ Infectious and Tropical Diseases Research Center, Department of Medical Mycology, School of Medicine, \\ Jundishapour Medical Sciences University, Ahwaz, Iran.
}

Accepted 30 May, 2011

\begin{abstract}
The aims of present study were to analysis of chemical compositions and evaluate anti-Candida activity of Dittrichia gravolence essential oil. The composition of the hydrodistilled essential oil from aerial parts of $D$. graveolens (L.) Greuter were grown in Iran investigated by gas chromatography-mass spectroscopy (GC/ MS). The major components, among the identified 22, were 1,8 Cineol (54.89\%), PCymen (16.2\%), [beta]-pinene (6.94\%) and Borneol (5.44\%). Anti-Candida activity of the volatile oil of the aerial parts of $D$. gravolence against different isolates of Candida albicans was studied in vitro. AntiCandida activity was done using serial dilutions of volatile oil in Sabouraud's dextrose agar (SDA). Agar well diffusion methods was used for detection minimum inhibitory concentration (MIC). MIC for 10 isolates of tested yeasts was $30.675 \mathrm{mg} / \mathrm{ml}$.
\end{abstract}

Key words: Dittrichia graveolens, essential oil, 1,8 Cineol, Candida albicans.

\section{INTRODUCTION}

The interest in the study of medicinal plants as a source of pharmacologically active compounds has increased worldwide. It is recognized that in some developing countries, plants are the main medicinal source to treat infectious diseases. Approximately, $20 \%$ of the plants found in the world have been submitted to pharmacological or biological test, and a substantial number of new antibiotics introduced on the market are obtained from natural or semi-synthetic resources. Cutaneous fungal infections are common diseases in humans, and can also be caused by dermatophytic fungi and some yeasts. Candida albicans is an opportunistic pathogen that can cause local and systemic infections in predisposed persons, commonly affecting immunologically compromised patients and those undergoing prolonged antibiotic treatment. Yet, the information available on plants, particularly medicinal plants, active against this yeast has, until recently, not resulted in effective formulations for either human or

\footnotetext{
*Corresponding author. E-mail: aghelnas@yahoo.com.
}

animal use (Duarte et al., 2005) Superficial candidiasis is a common infection of the skin, oral cavity and esophagus, and vagina, although most infections occur in patients debilitated or who are immunocompromised. $C$. albicans is responsible for many of these infections, and generally infect the skin, nails, or mucous membranes (Hall, 1999; Eggimann et al., 2003). Essential oils of aromatic plants species are used in industries for the production of soaps, perfumes and toiletries. Many of them are also used in traditional medicine for various purposes. Investigations concerning the evaluation of the biological activities of essential oils of some medicinal plants have revealed that some of them exhibited antibacterial, antifungal and insecticidal properties (Burt, 2004). Because of the antimicrobial properties showed by essential oils, the aromatherapy has been used for treatment of serious skin diseases, in special, superficial mycoses (Harris, 2002).

The small genus Dittrichia (Compositae, tribe Inulae) was previously considered as a section of Inula (Ball, 1976). Dittrichia graveolens (L.) W. Greuter [Syn. Inula graveolens (L.) Desf.] is one of the most conspicuous plants of the late summer flowering in large profusion 
from September to December. It grows along road sides, on waste grounds, in humid soil and near subsalt lands. This plant is an annual plant that grows about $80 \mathrm{~cm}$ high. The stems are covered with small, soft hair, the leaves are oval and pointed, the roots are fleshy and flowers are small, yellow and have the smell of camphor. The plant, widespread in the Mediterranean area, has been chemically investigated and several pharmacologically active sesquiterpenes (Topçu et al., 1993; Öksüz and Topçu, 1992; Lanzetta et al., 1991; Rustaiyan et al., 1987), flavonoids (Soulelesand and Philianos, 1979), and aromatic compounds (Topçu et al., 1993) have been isolated. The essential oil is known as the most effective oil for loosening mucous and deep congestion. It is also useful for acute and chronic respiratory conditions such as coughs, colds, sinusitis laryngitis and bronchitis. Only one work has been done on $D$. graveolens aerial part essential oil collected from north of Iran (Mirza and Ahmadi, 2000). The aim of present study was to identify the chemical compositions of the aerial parts essential oil of $D$. gravolens grown in Khuzestan, south-west of Iran. Also, in order to estimate the possibility of using it as an antifungal agent for skin diseases (cutaneous candidiasis and dermatomycosis), the antifungal activity of this oil against $C$. albicans was studied.

\section{MATERIALS AND METHODS}

\section{Plant material}

Aerial parts of $D$. graveolens were collected during the flowering stage from Shush (latitude $32^{\circ} 11^{\prime} 21^{\prime \prime} \mathrm{N}$, longitude $48^{\circ} 15^{\prime} 28^{\prime \prime} \mathrm{E}$, Khuzestan Province, Iran) in September 2006. Voucher specimens have been deposited in the Department of Pharmacognosy, School of Pharmacy, Ahwaz Jundishapour Medical Sciences University, Ahwaz, Iran. Air-dried aerial parts were subjected to hydrodistillation using a Clevenger-type apparatus for $3 \mathrm{~h}$ to yield $0.08 \% \mathrm{v} / \mathrm{w}$ of yellowish oil. The obtained oil with a distinct odor was collected in pentane $(1 \mathrm{ml})$, dried over anhydrous sodium sulphate and was stored under $\mathrm{N}_{2}$ atmosphere in amber vials at $4^{\circ} \mathrm{C}$ until analysis. The oil was analyzed within $24 \mathrm{~h}$ from its production.

The oil was analyzed by gas chromatography-mass spectroscopy (GC/MS) using a Thermoquest-Finnigan GC/MS system operating in the $\mathrm{EI}$ mode at $70 \mathrm{eV}$, equipped with a DB-5 capillary column (60 $\mathrm{m} \times 0.25 \mathrm{~mm}$, film thickness $0.25 \mu \mathrm{m}$ ). The initial temperature of the column was $60^{\circ} \mathrm{C}$ and was heated to $280^{\circ} \mathrm{C}$ with a $5^{\circ} \mathrm{C} / \mathrm{min}$ rate. Carrier gas $\mathrm{He}$, flow rate $1 \mathrm{ml} / \mathrm{min}$. Split ratio 1:5. The injection volume was $1 \mu \mathrm{l}$. n-Alkanes were used as reference points in the calculation of the relative retention indices (RRI). The identification of the chemical constituents was based on comparisons of their retention times and mass spectra with those obtained from authentic samples and/or the NIST/NBS, Wiley libraries' spectra as well with literature data (Adams, 2001).

\section{Fungal isolates}

Teen strains of $C$. albicans (isolated from different patients) were studied. All $C$. albicans isolates were identified by standard methods, which included identification based on germ tube test, production chlamydoconidia on corn meal agar (Difco, UK), API 20
C AUX (bioMerieux SA, France) and CHROMagar Candida (CHROMagar Candida Company, Paris, France). Isolates were stored as suspensions in sterile water at ambient temperature for future use.

\section{Susceptibility tests}

Anti fungal activity of $D$. graveolens essential oil was investigated by agar well diffusion method (Shahidi et al., 2005). The isolates were subcultured onto Sabouraud's dextrose agar, SDA (Merck, Germany) and incubated at $37^{\circ} \mathrm{C}$ for $24 \mathrm{~h}$. Suspensions of yeasts were prepared in sterile PBS and adjusted to a concentration of $10^{6}$ cells/ml. Dipping a sterile swab into the fungal suspension and rolled on the surface of the agar medium. The plates were dried at room temperature for $15 \mathrm{~min}$. Wells of $10 \mathrm{~mm}$ in diameter and about $7 \mathrm{~mm}$ apart were punctured in the culture media using sterile glass tube. $0.1 \mathrm{ml}$ of serial dilutions of fresh volatile oil was administered to fullness for each well. Plates were incubated at $37^{\circ} \mathrm{C}$. After $24 \mathrm{~h}$ incubation bioactivities were determined by measuring the diameter of inhibition zone diameter in $\mathrm{mm}$. All experiments were made in triplicate and means of MIC for 10 isolates of tested yeasts was calculated.

\section{RESULTS AND DISCUSSION}

Essential oil of $D$. graveolens was light yellow, liquid at room temperature with agreeable odour. The chemical composition of the oil extracted by hydrodistillation from aerial parts of the plant is reported in Table 1 together with the Kováts' Indices (KI) calculated for each compound, the percentage composition and the identified methods. A total of twenty two components added up to $98.69 \%$ of the oil was identified. The main constituents were 1,8 Cineol (54.89\%), P-Cymen (16.2\%), [beta]pinene $(6.94 \%)$ and Borneol (5.44\%). The oil components can be classified into monoterpene hydrocarbons (28\%), oxygenated monoterpenes $(66.70 \%)$ and sesquiterpene hydrocarbons $(3.99 \%)$. The oil of aerial parts of $D$. graveolens growing in Corsica showed the occurrence of 13 main components from which bornyl acetate and borneol (65.8 to $75.6 \%$ ) were the major compounds (Blanc et al., 2004). In other study, the hydro distillated essential oil of $D$. graveolens aerial parts was mainly made up of selin-11-en-4-a-ol (14.1\%), 1,10-di-epicubenol (10.3\%) and cedr-8(15)-en-9- $\alpha$-ol (Marongiu et al., 2003).

The most important compounds from the aerial part without flowers of plant gathered in Tunisia were I-cadinol $(9.2 \%)$, borneol $(21.4 \%)$ and bornyl acetate (33.4\%) whereas the main compounds found in the flower essential oil were camphene (5.5\%), I-cadinol (11.3\%), borneol (19.3\%) and bornyl acetate (39.6\%) (HarzallahSkhiri et al., 2005). The major constituents of the Greek $D$. graveolens aerial parts essential oil were epi-a-cadinol (30.2\%) and bornyl acetate (25.4\%) (Petropoulou et al., 2004). The chemical oil composition of the investigated sample exhibited interesting significant differences with that extracted from the air-dried aerial parts of $D$. graveolens collected from north of Iran, reported 
Table 1. Percentage composition of the essential oil of aerial parts of Dittrichia graveolens

\begin{tabular}{|c|c|c|c|}
\hline Compound & RT (min) & $\mathbf{R I}$ & Percentage \\
\hline a-Pinene & 9.3 & 936 & 3.21 \\
\hline$\beta$-Pinene & 10.29 & 977 & 6.94 \\
\hline Myrcene & 10.43 & 983 & 0.2 \\
\hline$\alpha$-Phellandrene & 10.90 & 1002 & 0.89 \\
\hline p-Cymene & 11.28 & 1016 & 16.2 \\
\hline 1,8-Cineol & 11.54 & 1026 & 54.89 \\
\hline $\mathrm{y}$-Terpinene & 12.26 & 1052 & 0.56 \\
\hline Linalool & 13.25 & 1089 & 0.51 \\
\hline Undecane & 13.50 & 1098 & 0.28 \\
\hline Fenchol & 13.70 & 1105 & 0.37 \\
\hline Trans-Pinocarveol & 14.41 & 1131 & 1.69 \\
\hline Pinocarvone & 14.84 & 1146 & 0.53 \\
\hline Borneol & 15.10 & 1156 & 5.44 \\
\hline Terpin-4-ol & 15.43 & 1168 & 1.37 \\
\hline a-Terpineol & 15.71 & 1178 & 1.31 \\
\hline Myrtenol & 15.91 & 1185 & 0.35 \\
\hline Dodecane & 16.25 & 1197 & 0.25 \\
\hline Bornyl acetate & 18.33 & 1274 & 0.24 \\
\hline Tridecane & 18.95 & 1297 & 0.19 \\
\hline$\beta$-Caryophyllene & 22.78 & 1428 & 1.58 \\
\hline a-Humulene & 26.09 & 1583 & 1.99 \\
\hline a-Muurolene & 27.21 & 1640 & 0.42 \\
\hline Total & -- & -- & 98.69 \\
\hline
\end{tabular}

$\mathrm{RT}=$ Retention time, $\mathrm{KI}=$ Kováts indices.

Table 2. MIC of $D$. graveolens essential oil for teen isolate of $C$. albicans.

\begin{tabular}{lcc}
\hline Isolate & MIC $\mathbf{( m g / m l )}$ & Zones of inhibition \\
\hline Candida albicans (1) & 31.04 & 13 \\
Candida albicans (2) & 30.14 & 12 \\
Candida albicans (3) & 29.16 & 11 \\
Candida albicans (5) & 28.84 & 10 \\
Candida albicans (7) & 31.92 & 13 \\
Candida albicans (8) & 31.43 & 13 \\
Candida albicans (9) & 32.06 & 13 \\
Candida albicans (10) & 31.18 & 12 \\
Candida albicans (11) & 30.96 & 12 \\
Candida albicans (12) & 30.02 & 12 \\
Total & 306.75 & \\
X & 30.675 & \\
SD & 1.043 & \\
\hline
\end{tabular}

previously by Mirza et al. (2000). It was mainly constituted of borneol (60.7\%), bornyl acetate $(6.8 \%), \beta$ Caryophyllene (8.3\%), I-cadinol (5.2\%) and caryophyllene oxide $(4.3 \%)$. This study shows clearly the effect of the plant origin on the composition of the corresponding essential oil.
Numerous essential oils have been tested for in vivo and in vitro antimycotic activity and some demonstrated to be potential antifungal agents. Their mechanism of action appears to be predominantly on the fungal cell membrane, disrupting its structure causing leakage and cell death; blocking the membrane synthesis; inhibition of 
the spore germination, fungal proliferation and cellular respiration (Harris, 2002). Because of high volatility and lipophilicity of the essential oils, they are readily attached to penetrate into the cell membrane to exert their biological effect (Inouye, 2003). In the present study the anti Candida activities of the essential oil of $D$. graveolens were evaluated against teen isolates of $C$. albicans by agar well diffusion method. Several concentrations of the essential oil of $D$. graveolens were applied on isolates. The results showed remarkable activities against tested isolates. Table 2 shows details of mean MICs of essential oil of $D$. graveolens against fungal isolates. As shown the lowest MIC for teen isolates of C. albicans was $28.84 \mathrm{mg} / \mathrm{ml}$, totally the MIC for 10 isolates of $C$. albicans was $30.675 \mathrm{mg} / \mathrm{ml}$.

\section{ACKNOWLEDGEMENT}

This work was a Pharm-D Thesis and supported by Research Council of Jundishapour Medical Sciences University, Ahwaz, Iran (Grant no. 85U012).

\section{REFERENCES}

Duarte MCT, Figueiral GM, Sartoratto A, Rehder VLG, Delarmelina C (2005). Anti-Candida activity of Brazilian medicinal plants. J. Ethnopharmacol., 97: 305-311.

Hall JC (1999). Sauer's manual of skin diseases. 8. ed. Philadelphia: Lippincot Williams and Wilkins,

Eggimann P, Garbino J, Pittet D (2003). Epidemiology of Candida species infections in critically ill non-immunosuppressed patients. Lancet. Infect. Dis., 3: 685-702.

Burt S (2004). Essential oils: their antibacterial properties and potential applications in foods-a review. Int. J. Food Microbiol., 94: 223-253.

Harris R (2002). Progress with superficial mycoses using essential oils. Int. J. Aromather., 12: 83-91.

Ball PW, Dittrichia W (1976). Greuter. In: Flora Europaea. Edits., Tutin TG, Heywood VH, Surges NA, Moore DM, DValentine DH, Waltersand SM, Webb DA. Vol. 4. Cambridge: Cambridge University Press, pp. 136-137.
Topçu G, Öksüz S, Shieh HL, Cordell GA, Pezzuto JM, BozokJohansson C (1993). Cytotoxic and antibacterial sesquiterpenes from Inula graveolens. Phytochemistry, 33: 407-410.

Öksüz S, Topçu G (1992). A eudesmanolide and other constituents from Inula graveolens. Phytochemistry. 31: 195-197.

Lanzetta R, Lama G, Mauriello G, Parrilli M, Racioppi R, Sodano G (1991). Ichthyotoxic sesquiterpenes andxanthanolides from Dittrichia graveolens. Phytochemistry, 30: 1121-1124.

Rustaiyan A, Jakupovic J, Chau-Thi TV, Bohlmann F, Sadjadi A (1987). Further sesquiterpene lactones from the genus Dittrichia. Phytochemistry. 26: 2603-2606.

Soulelesand CH, Philianos S (1979). Chemical constituents of Inula graveolens Dest. Fitoterapia. 251-254.

Mirza M, Ahmadi L (2000). Composition of the Essential oil of Dittrichia graveolens (L.) Greuter. J. Essent. Oil. Res., 12: 507-508.

Adams RP (2001). Identification of Essential Oil Components by Gas Chromatography/Quadropole Mass Spectroscopy. $3^{\text {rd }}$ ed. Illinois: Allured Publlishing Corporation.

Shahidi Bonjar GH, Aghighi S, Karimi Nik A (2005). Antibacterial and Anti fungal Survey in Plants used in Indigenous Herbal-Medicine of South East Regions of Iran. J. Biol. Sci., 4: 405-412.

Blanc MC, Muselli A, Bradesi P, Casanova J (2004). Chemical composition and variability of the essential oil of Inula graveolens from Corsica. Flavour. Fragrance. J., 19: 314-319.

Marongiu B, Piras A, Pani F, Porcedda S, Ballero M (2003). Extraction, separation and isolation of essential oils from natural matrices by supercritical $\mathrm{CO}_{2}$. Flavour. Fragrance. J., 18: 505-509.

Harzallah-Skhiri F, Chéraif I, Ben Jannet H, Hammami M (2005). Chemical composition of essential oils from leaves-stems, flowers and roots of Inula graveolens from Tunisia. Pakistan. J. Biol. Sci., 8: 249-254.

Petropoulou A, Tzakou O, Verykokidou E (2004). Volatile Constituents of Dittrichia graveolens (L.) Greuter from Greece. J. Essen. Oil Res., 16: 400-401.

Inouye S (2003). Laboratory evaluation of gaseous essential oils (part 1). Int. J. Aromather., 13: 95-107. 